\title{
TERRESTRIAL DIGITAL RADIO SERVICES IN EUROPE
}

\author{
Branimir Jakšić1, , \\ Jelena Todorović ${ }^{1}$ \\ Vladimir Maksimović ${ }^{1}$ \\ Petar Spalević2, \\ Ratko Ivković1 \\ ${ }^{1}$ Faculty of Technical Sciences, \\ University of Pristina, \\ Kosovska Mitrovica, Serbia \\ ${ }^{2}$ Singidunum University, \\ Belgrade, Serbia
}

\begin{abstract}
:
The paper presents an overview of terrestrial digital radio services in Europe. The first is presented the overview of the digital radio characteristics in Europe, which includes year of start experimental and regular broadcasting digital radio, the standards used for digital radio, the number of active multiplexes (national, regional and local) as well as the area coverage. After that is presented number of radio stations which emitting simulcast in the analog $\mathrm{FM}$ and digital $\mathrm{DAB}(\mathrm{DAB}+)$ standard and number of radio stations which emitting exclusively in the $\mathrm{DAB}(\mathrm{DAB}+)$ standard. In the end is presented comparison of data from 2014 and 2019 relating to the percentage of population covered by $\mathrm{DAB} / \mathrm{DAB}+$ signal, the total number of $\mathrm{DAB}$ and $\mathrm{DAB}+$ services, services number in the $\mathrm{DAB}$ standard and the number of stations in the $\mathrm{DAB}+$ standard.
\end{abstract}

Keywords:

Digital Audio Broadcasting, DAB, DAB+, digital radio.

\section{INTRODUCTION}

DAB (Digital Audio Broadcasting) is a family of digital standards for broadcasting digital audio and multimedia signals. $\mathrm{DAB}$ consists of DAB and $\mathrm{DAB}+$ standards, which serve for digital broadcasting audio signals via radio and DMB (Digital Multimedia Broadcasting) standard, which represents the upgrade of DAB in the form of multimedia capabilities [1].

DAB began to develop in 1981, and since 2000 it has been under the authority of the independent international organization "World DAB Forum". This organization is concerned with the implementation and promotion of DAB, cooperates and coordinates with radio broadcasters, network service providers, equipment manufacturers, governments and competent state authorities.

Based on the RRC-06 (Regional Radio-communication Conference) held in Geneva in 2006 organized by the ITU (International Telecommunication Union), a new international agreement pf frequency planning for digital broadcasting radio and television programs has been established and adopted. On the basis of this agreement, a frequency plan for the realization of the digital radio was adopted, so that all European countries received the predicted frequencies for the broadcasting digital radio.
Correspondence:

Branimir Jakšić

e-mail:

branimir.jaksic@pr.ac.rs 
The transition from analog to digital broadcasting radio using $\mathrm{DAB}$ standards brings advantages, such as $[1,2]$ :

- better use of the frequency spectrum (broadcasting multiple programs on one radio frequency, ie multiplex),

- broadcasting radio stations using same frequency on a large area using the Single Frequency Network (SFN);

- providing additional services,

- broader selection of radio stations, better sound quality (approximate to studio sound),

- interactivity,

- significant savings in transmission costs.

\section{FEATURES AND DAB SERVICES}

For the radio transmission of the DAB signal, two frequency bands are provided:

- VHF-III band, in the range of $174-230 / 240 \mathrm{MHz}$ and

- L-band, in the range from 1452 to $1492 \mathrm{MHz}$, used in countries where the VHF-III band (Band III) is not yet available or as an additional distribution band, with the width of a single multiplex channel of $1.5 \mathrm{MHz}$ [3].

The DAB standard is based on MPEG Audio Layer 2 coding, which is still used in broadcasting. An improved version of this encoding is MPEG Layer 3. The DAB+ standard is more efficient than the DAB standard. It uses the MPEG-4 High Efficiency AAC v2 profile (codec, known as HE-AAC v2) and it is the most efficient available audio compression scheme in the world and allows up to three times more multiplex services than the original DAB $[1,4,5]$.

Geographical coverage area of radio services that use HE-AAC v2 is larger than the radio services that use MPEG Audio Layer 2. The multimedia information transmitted through the HE-AAC v2 radio service is much better protected against transmission errors than the radio service that use MPEG Audio Layer 3 codec. Audio bit rate range is from $32 \mathrm{~kb} / \mathrm{s}$ to $384 \mathrm{~kb} / \mathrm{s}$ [6,7].

Besides the basic function, the transmission of audio signals, DAB supports the following additional services:

- EPG (Electronic Program Guide) - is designed to offer similar services like TV EPG but for radio and related data transmission services.
- Slideshow - uses standard formats of Web images and standard Web publishing tools to enhance the radio program and visualize it. All standard formats such as JPEG, PNG or APNG (Animed PNG) can be broadcast by DAB without losing audio and video synchronization.

- TCM / TPEG (Traffic and Travel Information / Transport Protocol Experts Group) - was formed due to increased demand for more accurate and timely traffic and travel information) and serves to send information on traffic and roads. Regardless of the fact that the RDS / TMC (Radio Data System / Traffic Message Channel) technology has been quite successful in various European countries, it has certainly shown its limitations due to the limited RDS bandwidth. Implementation of the $\mathrm{DAB}$, and later of the DMB standard offers enormous opportunities as a carrier for improved traffic and travel services, such as: traffic occasions/news, weather in traffic, driver assistance, parking information, local hazard alerts, traffic density, etc.

- Journaline, is a relatively new data transmission service, which is internationally standardized by the World DMB Forum. Basic functionality similar to electronic journal or teletext in TVs.

- Broadcast Website, serves for broadcasting Web site applications. Allows the transsmision of complete Web sites for offline use to a digital radio receiver, which should have Web browsing software. Besides to the related HTML pages, in the offer can be multimedia elements in the form of images, animated graphics, $\mathrm{mp} 3$ or video files.

A large percentage of radio listeners are still in cars and digital radio broadcasting industries around the world investing heavily in involving the automotive sector in their plans. Every year, WorldDAB holds annual European automotive manifestations. These events bring together distributors, manufacturers and automotive industries from different markets to share knowledge and look for the best practical solution for digital radio in cars, as well as drivers' expectations [8].

\section{OVERVIEW OF THE MAIN DIGITAL RADIO CHARACTERISTICS}

Table 1 shows an overview of the main digital radio characteristics in Europe that includes the year of start experimental and regular broadcasting digital radio, the 
standards used for digital radio, the number of active multiplexes (national, regional and local) as well as the area coverage. Data refer to March 1, 2019. and were collected from the official websites of the national bodies responsible for the radio digitization and telecommunications regulations in [8-39].

Table 1. Overview of the main digital radio characteristics

\begin{tabular}{|c|c|c|c|c|c|c|c|}
\hline \multirow{2}{*}{ Country } & \multirow{2}{*}{ Experimental } & \multirow{2}{*}{ Regular } & \multirow{2}{*}{ Standard } & \multicolumn{3}{|c|}{ MUX number } & \multirow{2}{*}{$\begin{array}{c}\text { Coverage } \\
{[\%]}\end{array}$} \\
\hline & & & & $\mathbf{N}$ & $\mathbf{R}$ & $\mathbf{L}$ & \\
\hline United Kingdom & 1993 & 1999 & $\mathrm{DAB} / \mathrm{DAB}+$ & 3 & 10 & 61 & 97.3 \\
\hline Norway & 1995 & 1999 & $\mathrm{DAB} / \mathrm{DAB}+$ & 1 & 7 & 7 & 99.7 \\
\hline Sweden & 1995 & 2012 & $\mathrm{DAB} / \mathrm{DAB}+$ & 1 & 1 & - & 41.8 \\
\hline Denmark & 1995 & 2002 & $\mathrm{DAB} / \mathrm{DAB}+$ & 2 & - & 1 & 98 \\
\hline Germany & 1995 & 1999 & $\mathrm{DAB}+$ & 1 & 26 & 4 & 97 \\
\hline Poland & 1996 & 2013 & $\mathrm{DAB}+$ & - & 17 & 6 & 56 \\
\hline Ireland & 1998 & 2006 & DAB & 1 & 1 & - & 52 \\
\hline Belgium & 1998 & 2012 & $\mathrm{DAB} / \mathrm{DAB}+$ & - & 3 & - & 95 \\
\hline Spain & 1998 & 2011 & $\mathrm{DAB} / \mathrm{DAB}+$ & 3 & - & - & 20 \\
\hline Italy & 1998 & 2012 & $\mathrm{DAB}+$ & 3 & - & 8 & 80 \\
\hline Austria & 1999 & 2018 & $\mathrm{DAB}+$ & - & 1 & - & 29 \\
\hline Switzerland & 1999 & 2009 & $\mathrm{DAB} / \mathrm{DAB}+$ & 4 & 3 & 2 & 99.5 \\
\hline Netherlands & 2004 & 2008 & $\mathrm{DAB}+$ & 2 & 5 & - & 95 \\
\hline Malta & 2004 & 2006 & $\mathrm{DAB}+$ & 3 & - & - & 100 \\
\hline Slovenia & 2006 & 2016 & $\mathrm{DAB}+$ & 1 & - & - & 73 \\
\hline Czech Republic & 2007 & 2011 & $\mathrm{DAB}+$ & - & 1 & 3 & 62 \\
\hline France & 2010 & 2015 & $\mathrm{DAB}+$ & - & 15 & 3 & 21.3 \\
\hline Hungary & 2008 & - & $\mathrm{DAB}+$ & 1 & - & - & 30 \\
\hline Romania & 2015 & - & $\mathrm{DAB}$ & - & 1 & - & 10.4 \\
\hline Slovakia & 2015 & - & $\mathrm{DAB}+$ & - & - & 6 & 38 \\
\hline Croatia & 2017 & - & $\mathrm{DAB}+$ & 1 & - & - & 70 \\
\hline Turkey & 2017 & - & $\mathrm{DAB}+$ & - & - & 1 & 21.5 \\
\hline Ukraine & 2018 & - & $\mathrm{DAB}+$ & - & - & 1 & 7.1 \\
\hline Greece & 2018 & - & $\mathrm{DAB}+$ & - & 1 & - & NA \\
\hline Luxembourg & 2018 & - & $\mathrm{DAB}+$ & - & - & 1 & 100 \\
\hline Serbia & 2018 & - & $\mathrm{DAB}+$ & - & 1 & - & 28 \\
\hline
\end{tabular}

a.N - National, R- Regional, L - Local

The first tests of digital radio began in the 1990s. In some countries (Poland, Ireland, Belgium, Spain, Italy and Austria), the process from experimental to regular broadcasting included a longer time period (more than 15 years). In the last few years, some of countries that did not have digital radio services, they started broadcasting. Besides to the countries listed in Table 1, Bulgaria and Estonia occasionally experimentally broadcast digital radio services. Portugal, Bosnia and Herzegovina, North Macedonia, Montenegro, Albania, Finland,
Moldova, Lithuania and Latvia are countries that do not currently broadcast digital terrestrial radio in Europe.

It is mainly applied $\mathrm{DAB}+$ standard or in combination with the $\mathrm{DAB}$ standard. All countries that have started broadcasting in the $\mathrm{DAB}$ standard tend to switch to advanced $\mathrm{DAB}+$. The $\mathrm{DAB}$ standard is currently exclusively represented in Romania and Ireland. The number and types of the multiplex are different. The most common are regional multiplexes, with the largest number of multiplexes being activated in United Kingdom, Germany, Poland and France. 
The largest coverage of the population by DAB signal was achieved in Malta, Norway, Switzerland, Denmark, Germany and United Kingdom, which have almost $100 \%$ coverage of the population.

\section{OVERVIEW OF DAB AND DAB+ SERVICES}

Table 2 shows the number of DAB and DAB + in European countries. The number of radio stations emitting simulcast in the analog FM and digital DAB (DAB+) standard and the number of radio stations emitting exclusively in the $\mathrm{DAB}(\mathrm{DAB}+)$ standard is given [8-39].
From Table 2 it can be seen that most digital terrestrial radio station are broadcast in United Kingdom, as many as 495. Next are France, Norway, Denmark, Italy, Switzerland, which broadcast more than 100 digital radio channels. Also, it can be seen that broadcasting in the DAB standard is the most represented in United Kingdom, while other countries generally broadcast radio services in the $\mathrm{DAB}+$ standard (the $\mathrm{DAB}$ standard is slightly or not at all included). Romania and Ireland broadcast services exclusively in the DAB system. The number of radio stations is directly related to the number of multiplexes shown in Table 1.

Table 2. Number of DAB and DAB+ services

\begin{tabular}{|c|c|c|c|c|c|c|c|}
\hline \multirow[b]{2}{*}{ Country } & \multicolumn{3}{|c|}{$\mathrm{DAB}$} & \multicolumn{3}{|c|}{$\mathrm{DAB}+$} & \multirow{2}{*}{$\begin{array}{c}\text { Total } \\
\text { DAB and } \\
\text { DAB+ }\end{array}$} \\
\hline & $\begin{array}{c}\text { simulcast } \\
\text { FM and } \\
\text { DAB }\end{array}$ & $\begin{array}{c}\text { exclusively } \\
\text { DAB }\end{array}$ & Total & $\begin{array}{c}\text { simulcast } \\
\text { FM and } \\
\text { DAB+ }\end{array}$ & $\begin{array}{c}\text { exclusively } \\
\text { DAB+ }\end{array}$ & Total & \\
\hline $\begin{array}{c}\text { United } \\
\text { Kingdom }\end{array}$ & 329 & 158 & 487 & 1 & 7 & 8 & 495 \\
\hline Norway & 1 & 1 & 2 & 20 & 193 & 213 & 215 \\
\hline Sweden & 1 & 9 & 10 & 14 & 2 & 16 & 26 \\
\hline Denmark & 7 & 7 & 14 & 11 & 3 & 14 & 28 \\
\hline Germany & - & - & - & 110 & 40 & 150 & 150 \\
\hline Poland & - & - & - & 21 & 7 & 28 & 28 \\
\hline Ireland & 5 & 5 & 10 & - & - & - & 10 \\
\hline Belgium & 12 & 4 & 16 & 11 & 1 & 12 & 28 \\
\hline Spain & 18 & 0 & 18 & 1 & 0 & 1 & 19 \\
\hline Italy & - & - & - & 116 & 20 & 136 & 136 \\
\hline Austria & - & - & - & 4 & 11 & 15 & 15 \\
\hline Switzerland & 6 & 9 & 15 & 80 & 41 & 121 & 136 \\
\hline Netherlands & - & - & - & 94 & 18 & 112 & 112 \\
\hline Malta & - & - & - & 53 & 0 & 53 & 53 \\
\hline Slovenia & - & - & - & 14 & 2 & 16 & 16 \\
\hline $\begin{array}{l}\text { Czech Re- } \\
\text { public }\end{array}$ & - & - & - & 16 & 13 & 29 & 29 \\
\hline France & - & - & - & 76 & 90 & 166 & 166 \\
\hline Hungary & - & - & - & 7 & 0 & 7 & 7 \\
\hline Romania & 5 & 1 & 6 & - & - & - & 6 \\
\hline Slovakia & - & - & - & 36 & 21 & 57 & 57 \\
\hline Ukraine & - & - & - & 9 & 5 & 14 & 14 \\
\hline Croatia & - & - & - & 15 & 1 & 16 & 16 \\
\hline Turkey & - & - & - & 8 & 0 & 8 & 8 \\
\hline Greece & - & - & - & 7 & 0 & 7 & 7 \\
\hline $\begin{array}{c}\text { Luxem- } \\
\text { bourg }\end{array}$ & - & - & - & 2 & 0 & 2 & 2 \\
\hline Serbia & - & - & - & 3 & 0 & 3 & 3 \\
\hline
\end{tabular}




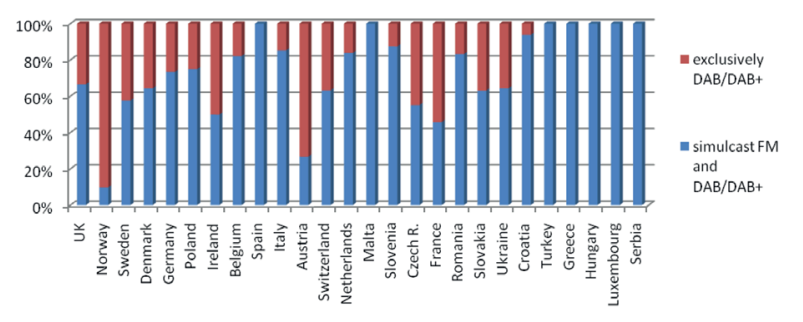

Fig. 1. Share of exclusively $\mathrm{DAB} / \mathrm{DAB}+$ and simulcast $\mathrm{DAB} / \mathrm{DAB}+$ services

Fig. 1 shows the share of exclusively $\mathrm{DAB} / \mathrm{DAB}+$ and simulcast $\mathrm{DAB} / \mathrm{DAB}+$ service in the countries of Europe. It can be seen that in almost all countries, a large number of stations emit simulcast in an analog FM standard and a digital DAB/DAB+ standard. The only exception is Norway, France and Austria, where a large number of radio stations are broadcast exclusively in digital format. Countries that have begun experimental DAB broadcast during 2018 do not yet have exclusive radio services that exclusively broadcast digital.

\section{COMPARATION OF DAB AND DAB+ SERVICES}

Fig. 2 shows a comparison of the \% coverage of the population with the $\mathrm{DAB} / \mathrm{DAB}+$ signal at the beginning of 2014 and March 1, 2019 [8-40]. Increased coverage with digital terrestrial radio signal in all European countries is evident. The largest percentage increase in coverage is represented in countries where $\mathrm{DAB}$ broadcasting started in the given period.

In Fig. 3, Fig. 4 and Fig. 5, a comparison of the number of services is shown: total $\mathrm{DAB}$ and $\mathrm{DAB}+$, only DAB and only DAB +, respectively, for 2014 and 2019. From the given figures can be seen increase of the number of digital radio services. The largest increase is in Norway, Netherlands, France and Slovakia.

From Fig. 4 it can be seen that the number of services using $D A B$ standard has decreased in the last five years (the exception is United Kingdom), while from Fig. 5 it can be seen that in all countries there was an evident increase in the number of services in the $\mathrm{DAB}+$ standard. The highest increse in the number of radio stations in the $\mathrm{DAB}+$ standard is in Norway, France and Slovakia. In the coming period, further increse of the more advanced $\mathrm{DAB}+$ standard is expected, which will completely suppress its previous $\mathrm{DAB}$ version.

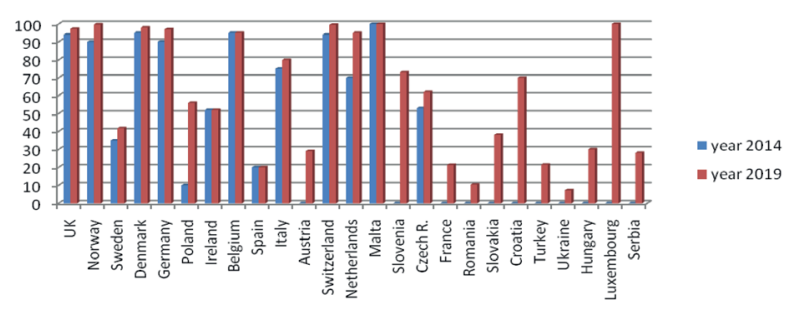

Fig. 2. DAB signals coverage in 2014 and 2019.

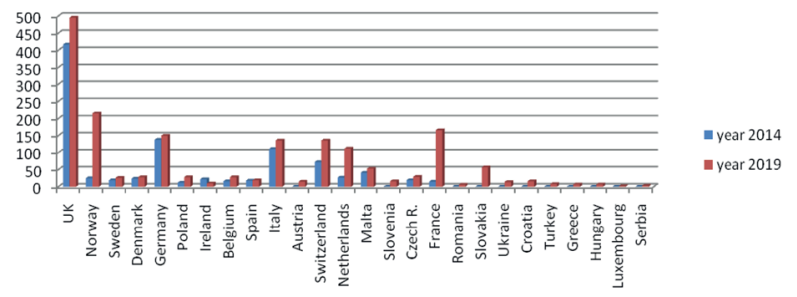

Fig. 3. Number of services (DAB and DAB+) in 2014 and 2019

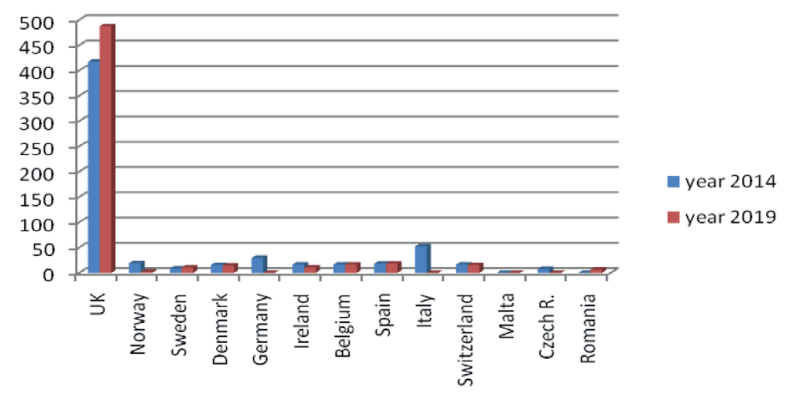

Fig. 4. Number of DAB service in 2014 and 2019

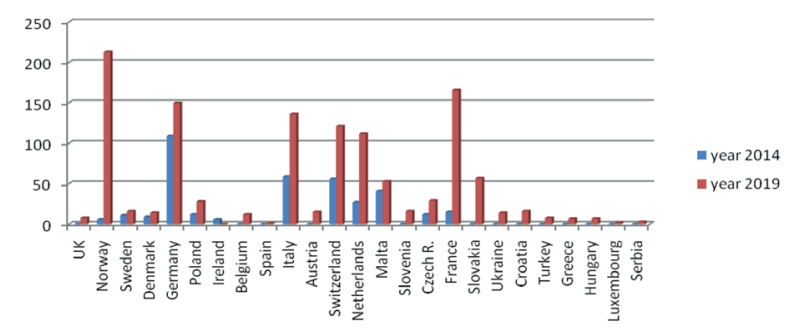

Fig. 5. Number of DAB+ service in 2014 and 2019 


\section{CONCLUSIONS}

A large number of European countries are currently broadcasting a digital radio signal, either on a regular or experimental basis. According to the number of radio stations in digital form in front of all countries United Kingdom is leading, while in terms of coverage of the population with the digital signal at the very top are Malta, Norway, Switzerland, Denmark, Germany and United Kingdom where coverage is greater than 95\%. Many countries are in transition from DAB to an upgraded $\mathrm{DAB}+$ standard, which allows the broadcast up to 28 radio stations in one multiplex, as opposed to $\mathrm{DAB}$ which allows up to 15 radio stations. All countries have plans to expand the digital network to equalize the coverage of analog and digital radio signals. In recent years, there is increasing of radio programs that are broadcast exclusively in digital form.

The transition to digital radio broadcasting is closely linked with the transition from analogue to digital TV broadcasting, because part of the VHF-III range is designed for digital radio that is used for analog TV broadcasting

Although the advantages of digital radio lead to its popularization, for now there is not yet a specific date for completely switching off the analogue radio network, except for United Kingdom and Norway that are planning to completely switch to digital broadcasting in 2020 .

\section{ACKNOWLEDGMENT}

This work was done in the framework of research projects of the Ministry of Science and Technological Development of the Republic of Serbia: TR32023 and TR35026.

\section{REFERENCES}

[1] W. Hoeg and T. Lauterbach, Digital Audio Broadcasting - Principles and Applications of Digital Radio. USA: John Wiley \& Sons Ltd, 2003.

[2] M. C. D. Maddocks, "Digital audio broadcasting (DAB)-radio for tomorrow," in IEE Colloquium on Audio Engineering, London, UK, 1994, pp. 4/1-4/2.

[3] G. V. Priya and P. Bharathi, "Optimization of reconfigurable $\mathrm{DAB} / \mathrm{DAB}+$ architecture using maximum likelihood path decoding," in 2014 Sixth International Conference on Advanced Computing (ICoAC), Chennai, 2014, pp. 97-101. doi: 10.1109/ ICoAC.2014.7229754
[4] M. Baek, "Design and Performance Evaluation of Digital Radio Measurement Test Beds for Laboratory Test: $\mathrm{DAB}, \mathrm{DAB}+$, and T-DMB Audio," in IEEE Transactions on Instrumentation and Measurement, vol. 62, no. 2, 2013, pp. 451-459. doi: 10.1109/ TIM.2012.2212602

[5] S. Baumgartner, Y. E. H. Shehadeh and G. Hirtz, "Performance evaluation of frequency and symbol timing offset estimation methods for $\mathrm{DAB} / \mathrm{DAB}+$ receivers under multipath fading channels," in 22nd International Conference on Software, Telecommunications and Computer Networks (SoftCOM), Split, 2014, pp. 321-325. doi: 10.1109/SOFTCOM.2014.7039113

[6] S. Lax, M. Ala-Fossi, P. Jauert and H. Shaw, "DAB: the future of radio. The development of digital radio in four European countries," in Media, Culture \& Society, SAGE Publications, vol. 30, no. 2, 2008, pp. 151-166.

[7] "Digital Audio Broadcasting (DAB) - Guide to DAB standards: ETSI TR 101495 V1.4.1 (201203)", European Telecommunications Standards Institute, European Broadcasting Union, 2012.

[8] World DAB Forum: http://www.worlddab.org/

[9] Independent regulator and competition authority for the UK communications industries: http://www. ofcom.org.uk/radio-broadcast-licensing/digital-radio/

[10] Digital radio UK: http://www.getdigitalradio.com.

[11] Digitalradio Norge AS: http://www.radio.no

[12] Myndigheten för press, radio och tv: http://www. mprt.se/en/

[13] The Ministry of Culture Denmark: http://kum.dk/

[14] Public Broadcaster - Danish Radio: http://www. dr.dk/radio/kanaler

[15] Digitalradio Deutschland: http://www.digitalradio. de

[16] The National Broadcasting Council: http://www.krrit.gov.pl/en/krrit/

[17] Digital Radio Ireland: http://www.digitalradio.ie

[18] Digital Radio: https://www.digitalradio.be/

[19] Ministerio de Industria, Energía y Turismo: http:// www.minetur.gob.es/telecomunicaciones/Espectro/ RadioTV/RD/Paginas/RD.aspx

[20] Digital Radio Italia: http://www.digitalradio.it/

[21] Euro DAB Italia: http://www.eurodabitalia.it

[22] DAB+ Austria: https://dabplus.at/

[23] Digital Radio CH: https://www.dabplus.ch/

[24] MCDT - Marketing and Consulting for Digital Broadcasting Technologies: http://www.mcdt.ch

[25] Digital Radio Netherlands: http://www.digitalradio. $\mathrm{nl}$ 
[26] Broadcasting Authority Malta: http://www.ba-malta.org/home

[27] Digitalni radio: https://digitalniradio.si/

[28] Regulator of spectrum, The Czech Telecommunication Office: http://www.ctu.cz

[29] DAB+ de Radio: https://www.dabplus.fr/

[30] The Conseil supérieur de l'audiovisuel (CSA): http:// www.csa.fr

[31] Digital Radio Hungary: http://www.digitalradio.hu/

[32] Societatea Națională de Radiocomunicații S.A: www.radiocom.ro

[33] Council for Broadcasting and Retransmission: http://www.rvr.sk

[34] Odašiljači i veze: https://www.oiv.hr/
[35] RTUK - The Radio and Television Supreme Council: https://www.rtuk.gov.tr/

[36] The National Council of Television and Radio Broadcasting of Ukraine:

[37] The National Council for Radio and Television (NCRTV): https://www.nrada.gov.ua/

[38] Emisiona tehnika i veze: http://www.etv.rs/

[39] Digital Radio Bulgaria: https://www.dab.bg/

[40] P. Spalević, B. Jakšić, M. Petrović, M. Milošević and M. Smilić, "Primena DAB standarda u digitalizaciji radija u Evropi," in Zbornik radova XIII međunarodnog naučno-stručnog simpozijuma INFOTEH 2014, Jahorina, Bosna i Hercegovina, 19-21 mart 2014, vol. 13, pp. 429-434 